\title{
Health, functionality, and social support in families with a child with a neurodevelopmental disorder - a pilot study
}

This article was published in the following Dove Press journal:

Neuropsychiatric Disease and Treatment

\author{
Diana Cavonius- \\ Rintahaka ${ }^{1,2}$ \\ Anna Liisa $\mathrm{Aho}^{3}$ \\ Arja Voutilainen ${ }^{2}$ \\ Eva Billstedt ${ }^{\prime}$ \\ Christopher Gillberg' \\ 'Gillberg Neuropsychiatry Centre, \\ Institute of Neuroscience and Physiology, \\ University of Gothenburg, Sahlgrenska \\ Academy, Gothenburg, Sweden; ${ }^{2}$ Child \\ Psychiatry, Neuropsychiatric Unit, \\ Helsinki University Hospital (HUH), \\ Helsinki, Finland; ${ }^{3}$ Faculty of Social \\ Sciences, Nursing Science, University of \\ Tampere, Tampere, Helsinki
}

Introduction: Several studies have reported that having a child with a neurodevelopmental disorder (NDD) increases parental stress and that parental psychosocial functioning influences child's development and behavior. It is unclear how parents of children with NDD experience family functionality, family health and receive support and if there are differences between experiences of mothers and fathers.

Methods: Families with children referred to a neurocognitive unit were invited to the study. A modified version of the FAmily Functionality, HEalth, and Social support (FAFHES) questionnaire was used. Open-ended questions were also included.

Results: Parents rated their social support lower than their family functionality and family health. Family functionality correlated positively with family health. No significant differences were found between mothers' and fathers' experiences. A three-months test-retest using the FAFHES showed no significant change in ratings of family functionality, family health, and social support.

Conclusions: Family functionality was connected to family health in families with a child with NDD. Mothers and fathers experienced their family health, family functionality, and received social support in similar ways.

Keywords: parents, family health, family functionality, social support, neurodevelopmental disorders

\section{Introduction}

Neurodevelopmental disorder (NDD) is a term used to describe neurological and psychiatric disorders with onset in early childhood. NDD includes learning and language disorders, motor coordination disorders, intellectual disabilities, autism spectrum disorder (ASD), attention-deficit/hyperactivity disorder (ADHD), tic disorders, and oppositional defiant disorder (ODD). Comorbidities are common and include sleeping disorders, feeding problems, and various sensory processing problems. A change of symptom/developmental profile may occur during the childhood period $^{1}$ which is emphasized in the concept of ESSENCE (Early Symptomatic Syndromes Eliciting Neurodevelopmental Clinical Examinations) coined by Gillberg. ${ }^{1,2}$ All NDDs are included under the ESSENCE umbrella. At least one in ten of all children has a diagnosable NDD.

ADHD manifests in the parents or siblings of children with an ADHD diagnosis 2-8 times more frequently than in the population in general. ${ }^{3}$ On average, the heritability of ADHD has been reported to be around $70 \%{ }^{4,5}$ Genetics have an
Correspondence: Cavonius-Rintahaka, D Gillberg Neuropsychiatry Centre, Institute of Neuroscience and Physiology, University of Gothenburg, Sahlgrenska

Academy, Gothenburg, Sweden

Tel +35840555 I5I I

Email diana.cavonius@hus.fi 
important role in the etiology of $\mathrm{ASD}^{6}$ and heritability of ASD is estimated to be approximately $80 \%{ }^{7}$ Consequently, having a child with NDD often means that other members of the family need support since the parent and/or one or several of the siblings in the family are likely to also have NDD or symptoms of NDD. ${ }^{8}$

Raising a child with NDD presents special challenges. Compared to parents with "typically" developing children, stress levels and parental tiredness are higher/more frequent. This affects family functioning. ${ }^{8,9}$ Parental stress appears to be even more pronounced when the child has an NDD with high level of comorbidity, ${ }^{10,11}$ and also when parents are older. ${ }^{11,12}$ Increased rates of depression ${ }^{13,14}$ and of depressive personality disorder have also been reported in parents of children with NDD compared to parents of "neurotypical" children. ${ }^{15,16}$ On the other hand, parental psychosocial health and family dysfunction influence the child's development regardless of whether the child has NDD or not. ${ }^{17,18}$

Families with children with NDD benefit from parental education programs. These should focus on enhancing parent communicative skills, provide psycho-education and behavioral management strategies. ${ }^{19}$ Interventions should also aim to help parents resolve possible emotional conflicts associated with their child's diagnosis ${ }^{20}$ and promote their own psychosocial well-being. ${ }^{18}$

According to some studies, there are differences between mothers' and fathers' ways to cope with their child's diagnosis and with stressful life events for example. ${ }^{12}$

In summary, parental stress, family dynamics, and family functionality are key issues to be considered when designing interventions for families with children with NDD. ${ }^{21,22}$ However, there is need for more knowledge regarding how families with a child with NDD are managing their daily lives.

In this study of families with children with NDD, we focused on the parents' subjective perspective on their own family health, family functionality, and on received support and what expectations they have regarding support. We also wanted to explore whether mothers and fathers had different or similar perspectives, and whether parental age had an impact. We used the FAmily Functionality, HEalth, and Social support (FAFHES) questionnaire that has been modified for use - for the first time - in this target group. Previously, FAFHES has been used only in families with cardiac patients and pediatric intensive care patients. ${ }^{23,24}$ The FAFHES is a check-list style questionnaire providing quantitative data. We also included some open-ended - freewriting - questions for qualitative analysis.
The first aim of the study was to report the experiences of parents of children with NDD in terms of family functionality, family health, and received support and their association with background data using the modified FAFHES questionnaire. We are particularly interested in how family health and function correlate with perceived social support. The second aim was to study over a three-month period whether there were any changes in parents' experience of family functionality, health, and social support. The third aim was to study parents' opinions about their expectations regarding support from health professionals.

\section{Methods}

\section{Procedure}

The data were collected at the neurocognitive outpatient clinic of the Child Neurology department at Helsinki University Hospital (HUH), which provide multidisciplinary assessments performed by child neurologists, neuropsychologists, nurses, occupational therapists, speech therapists, and social workers. After assessment at $\mathrm{HUH}$, a habilitation is carried out within HUH or at a clinic within the primary health care system.

Parents of children referred to the neurocognitive clinic at HUH for the first time were invited to take part in the study when they met the following inclusion criteria: biological parent or legal guardian living with a child (age 4-16 years) with suspected NDD, and having good language skills in Finnish, Swedish, or English and visiting HUH for the first time. Trained nurses at the clinic gave oral and written information about the study to the parents at the first visit and invited them to participate in the study.

Participation in the study included completing the FAFHES questionnaire (with some open-ended questions) that was mailed to both parents after written informed consent had been obtained. The envelope also included a prepaid envelope for returning the questionnaires by mail. Those who approved and completed the FAFHES questionnaire at the inclusion of the study received an additional FAFHES questionnaire for completion three months later. Reminder was sent to parents who did not return the second FAFHES questionnaire after 3 months.

\section{Participants}

The number of families who received detailed information about the study and who agreed to participate was 67 . However, only 29 (43\%) of these families actually sent back completed FAFHES questionnaire in the first round of data collection (Time 0 months). In total, 46 completed 
FAFHES questionnaires were returned (by 29 mothers and 17 fathers). The group which did not return the questionnaire was very similar in terms of children's diagnosis, gender, and age with the participating group. (Table 2)

For the three-months follow-up study (Time 3 months), 18 families $(62 \%$ of those who participated at Time 0 months, 18 mothers and 9 fathers) completed the FAFHES.

Families taking part of this study had children at the neurocognitive outpatient clinic of the Child Neurology department at HUH with following NDD diagnoses: delayed milestone, speech and language disorder, specific learning disorder, developmental coordination disorder, mixed specific developmental disorder, autistic disorder, attention deficit/hyperactivity disorder, selective mutism, Tourettes syndrome, and phobic anxiety disorder (Table 2).

\section{Instrument used}

The FAFHES questionnaire ${ }^{25}$ was developed for patients with cardiac disease and their family members with a view of studying their experiences regarding family functionality, health, and the social support received from staff at a hospital unit. The FAFHES has been tested since 2002, ${ }^{26}$ and used in several clinical contexts. ${ }^{23,27-29}$

The FAFHES instrument was modified for this study so as to be applicable in families of children with NDD. The permission to use and modify the instrument was obtained from the copyright holders.

In the modified FAFHES, certain questions have been changed (for example, the item nr.53 "Concern for the ill family member's condition causes distress in other family members" was changed to "The child's symptoms give rise to stress in other family members"). In this study, the FAFHES was used as a parent questionnaire.

The first section in the modified FAFHES instrument is related to demographic (age, marital status, and educational level) and background data (quality of family relationship, and mental health problems in the family, and how this affects the family). In this modified version, additional demographical items were added such as the frequency of NDD in the family. Background variables that were included in the analysis of association to family functionality, family health, and social support were age of the parent, number of siblings of the index child, quality of the relation between parents (Likert scale 1-5, 1=excellent, $5=$ very poor), experience of own current health (Likert scale $1-5,1=$ excellent, $5=$ =xtremely bad), age of onset of neurocognitive disorder problems in the index child, and experience of strength in being a parent (Likert scale 1-5, $1=$ extremely well, $5=$ extremely poorly).

The FAFHES then continues with three additional sections: 1) Family functionality (19 items), 2) family health (23 items), and 3) social support provided by professionals (21 items). The items are measured on Likert-type scale ranging from 1 (I disagree totally) to 6 (I agree totally). The internal consistency of the scale on the basis of Cronbach's alpha values was. 78-0.98. The modified FAFHES questionnaire also included three open-ended questions: 1) What kind of hopes and expectations do you have for the staff when they meet you and those close to you? 2) How would you like to develop the family interventions provided by the staff? 3) Is there anything else that you would like to add?

\section{Data analysis}

Statistical analysis was conducted with SPSS version 23. Descriptive statistics were used to describe the large number of quantitative data from FAFHES questionnaires. Family functionality, family health, and social support domain variables are reported from the parents' combined perspectives, but also mothers' and fathers' separate perspectives. The relationship between FAFHES domains was investigated using Pearson correlation coefficient, and Spearman correlation was used in studying background variables and FAFHES domains. Differences between family health, family functionality, and social support domains were analyzed using Paired Samples $t$-test, which could be used since the data were normally distributed. The MannWhitney test was used for dichotomous variables, and the Kruskall-Wallis test for categorical variables. The alpha level for statistical significance was set a priori at 0.05 .

The three additional semi-structured open-ended questions were analyzed following a research procedure using inductive content analysis. ${ }^{30}$ Predefined variables were not identified in advance. Parents' written responses were read and text that was relevant to the research question was highlighted. At the next stage, similar sentences were identified and classified to a "subcategory" (grouping and combining similar or related answers) and named close to the actual content received. Different themes were identified and subcategories were created. In the last stage, "main categories" were created from the subcategories focusing on similarities and differences close to the content received. The results are presented as four main categories (Table 4). Steps included in the qualitative analysis procedure were: 
1. Reading the responses.

2. Writing all respondents' answers under the three open-ended questions.

3. Creating condensed meaning units (description close to the text=reduction).

4. Grouping and combining similar or related answers.

5. Identifying themes and creating subcategories.

6. Creating main categories.

\section{Ethical approval}

The Medical Ethical Committee of Helsinki University Central Hospital approved the study (106/13/03/03/2012). All procedures performed in the study were in accordance with the ethical standards of the institutional research committee and with the 1964 Helsinki declaration and its later amendments or comparable ethical standards. Informed consent was obtained from all participants included in the study.

\section{Results}

\section{Demographic and background data of}

\section{parents and children}

Mean parental age was 40.5 years $(\mathrm{SD}=5.3)$, very similar for mothers and fathers. The majority (87\%) of the 29 families were married or cohabiting (Table 1), and $41 \%$ of the parents described the relation with the other parent as excellent. The majority of the parents (85\%) reported their own health being very good or good. Ten families (22\%) reported having one or more than one family member with a NDD. The majority of the parents (76\%) rated "extremely/quite well" on the item "How are you managing as a parent in daily life?" (Table 1).

In all, 30\% had visited another clinic or hospital regarding their child's NDD symptoms before coming to the neurocognitive clinic at $\mathrm{HUH}$, but for $70 \%$ of the families the visit to HUH was their first contact with a clinic for their child's NDD. At the time of the study, the number of visits to the HUH ranged from 1 to 3 in the study group.

During the daytime, the children were either at school $(\mathrm{n}=16,55 \%$ of the whole group), at daycare $(\mathrm{n}=10,35 \%)$, or at home $(n=3,10 \%)$. The diagnoses of the children at the HUH varied (Table 2). The majority of the parents (63\%) reported that the NDD symptoms often affected their children`s daily life.
Table I Demographic data of the study group.

\begin{tabular}{|c|c|c|}
\hline & $\mathbf{n}$ & $\%$ \\
\hline \multicolumn{3}{|l|}{ Relationship } \\
\hline Mothers/fathers & $29 /$ & $63 /$ \\
\hline & 17 & 37 \\
\hline \multicolumn{3}{|l|}{ Age of parents (mean age 40.5, SD 5.3 ) } \\
\hline$<40$-years old & 19 & 41 \\
\hline$\geq 40$-years old & 26 & 56 \\
\hline \multicolumn{3}{|l|}{ Marital status } \\
\hline Married/cohabiting & 40 & 87 \\
\hline Do not live together (including I widowed) & 6 & 13 \\
\hline \multicolumn{3}{|l|}{ Quality of the relationship between parents } \\
\hline Excellent & 19 & 41 \\
\hline Good & 17 & 37 \\
\hline Moderate & 7 & 15 \\
\hline Poor/very poor & 2 & 4 \\
\hline \multicolumn{3}{|l|}{ Basic education of parents } \\
\hline Comprehensive school & 14 & 30 \\
\hline Matriculation examination & 30 & 65 \\
\hline \multicolumn{3}{|l|}{ Professional education } \\
\hline No vocational qualification & 4 & 9 \\
\hline Basic-level qualification & 4 & 9 \\
\hline College-level education & 14 & 30 \\
\hline University degree/academic degree & 23 & 50 \\
\hline \multicolumn{3}{|l|}{ Numbers of children in family totally } \\
\hline I child & 2 & 4 \\
\hline 2 children & 20 & 43 \\
\hline 3 children & $\mathrm{II}$ & 24 \\
\hline$>4$ children & II & 24 \\
\hline \multicolumn{3}{|l|}{$\begin{array}{l}\text { Other members of the family have } \\
\text { neurocognitive disorders or diagnoses? }\end{array}$} \\
\hline Yes & 10 & 22 \\
\hline No & 34 & 74 \\
\hline \multicolumn{3}{|l|}{ Parents self-reported health } \\
\hline Very good/good & 39 & 85 \\
\hline Moderate & 6 & 13 \\
\hline Poor/very poor & 1 & 2 \\
\hline \multicolumn{3}{|l|}{ How are you managing as a parent in daily life? } \\
\hline Extremely/quite well & 35 & 76 \\
\hline Moderate & 10 & 22 \\
\hline Rather/extremely poorly & I & 2 \\
\hline \multicolumn{3}{|l|}{$\begin{array}{l}\text { Long-term illnesses or neuropsychiatric } \\
\text { disorders }\end{array}$} \\
\hline Yes & 10 & 22 \\
\hline No & 35 & 76 \\
\hline
\end{tabular}

Note: Number of the participants $(\mathrm{N}=46)$. 


\section{Parents' experience of family functionality, health, and social support}

The mean score for family functionality was $4.6(\mathrm{SD}=0.8)$, for family health $4.4(\mathrm{SD}=0.7)$, and for social support 3.7 $(\mathrm{SD}=1.3)$. No statistically significant differences were found between mothers and fathers in FAFHES (Table 3). There was a strong positive correlation between family functionality and family health $(\mathrm{r}=0.75, \mathrm{n}=46, p<0.001)$, a medium correlation between family health and social support $(\mathrm{r}=0.36, \mathrm{n}=43$, $p=0.019$ ) whereas the correlation between social support and family functionality was non-significant $(\mathrm{r}=0.19, \mathrm{n}=43$, $p=0.224$ ) (Table 3).

\section{Associations between background data and FAFHES domains}

No correlation was found between parental age and FAFHES or amount of siblings and FAFHES. Negative correlations were found between family functionality and quality of relations between parent $(r s=-0.643, \mathrm{n}=45$, $p<0.001)$, experience of own health $(r s=-0.552, \mathrm{n}=46$, $p<0.001$ ), and age of onset neurocognitive disorder problems $(r s=-0.374, \mathrm{n}=43, p=0.014)$. Negative correlations were also found between family health and quality of relations between parent ( $r s=-0.331, \mathrm{n}=45, p=0.026$ ), and experience of own health $(r s=-0.420, \mathrm{n}=46, p<0.001)$. Finally, experience of strength in parenthood correlated to family health $(r s=-0.724, \mathrm{n}=46, \quad p<0.004)$ and family functionality $(r s=-0.636, \mathrm{n}=46, p<0.001)$.

\section{FAFHES follow-up over a three-month period}

The FAFHES shows no statistically significant changes in parents' experience of family functionality, health, and social support between the two measures performed over three-month period (Table 3).

\section{Open-ended questions}

Results of the open-ended questions part of the study were presented as four main categories that illustrate parents' hopes and expectations towards health care professionals (Table 4).

The first main category "Parents want dialogue" included the following subcategories "Interaction with staff", "Communication between professionals at school, daycare and hospital", "Hope to be listened to", and "Hope to get more time from personnel". Parents wrote for example "I hope to have more time for discussion with staff".
Table 2 Characteristics of the children taking part in the study $(n=29)$ and of the children not taking part in the study $(n=36)$.

\begin{tabular}{|c|c|c|c|c|}
\hline \multirow[t]{2}{*}{ Participating group } & \multirow[b]{2}{*}{$\mathbf{n}$} & \multirow[b]{2}{*}{$\%$} & \multicolumn{2}{|c|}{$\begin{array}{l}\text { Non- } \\
\text { partici- } \\
\text { pating } \\
\text { group }\end{array}$} \\
\hline & & & $\mathbf{n}$ & $\%$ \\
\hline \multirow{2}{*}{\multicolumn{5}{|c|}{$\begin{array}{l}\text { Age of child (range } 4.6-16.1 \text {, SD } \\
3.2 \text {, average age } 8,5 \text { ) }\end{array}$}} \\
\hline & & & & \\
\hline$<7$ years old & 11 & $38 \%$ & 12 & $33 \%$ \\
\hline$\geq 7$ years old & 18 & $62 \%$ & 24 & $67 \%$ \\
\hline \multicolumn{5}{|l|}{ Gender of child } \\
\hline Girl & 5 & $17 \%$ & 9 & $25 \%$ \\
\hline Boy & 24 & $83 \%$ & 27 & $75 \%$ \\
\hline \multicolumn{5}{|l|}{ Daytime activity for child } \\
\hline In daycare & 10 & $35 \%$ & & \\
\hline At school & 16 & $55 \%$ & & \\
\hline Other & 3 & $10 \%$ & & \\
\hline \multicolumn{5}{|l|}{ Reasons for child referral } \\
\hline Delayed milestone & 2 & $7 \%$ & 7 & $19 \%$ \\
\hline Speech and language disorders & 3 & $10 \%$ & 5 & $14 \%$ \\
\hline Specific learning disorder & 8 & $29 \%$ & 9 & $25 \%$ \\
\hline $\begin{array}{l}\text { Developmental coordination } \\
\text { disorder }\end{array}$ & $\mathrm{I}$ & $3 \%$ & I & $3 \%$ \\
\hline $\begin{array}{l}\text { Mixed specific developmental } \\
\text { disorders }\end{array}$ & 6 & $21 \%$ & 7 & $19 \%$ \\
\hline Autistic disorder & 4 & $14 \%$ & I & $3 \%$ \\
\hline $\begin{array}{l}\text { Attention- deficit/hyperactivity } \\
\text { disorder }\end{array}$ & 2 & $7 \%$ & 4 & $11 \%$ \\
\hline Selective mutism & 1 & $3 \%$ & 0 & $0 \%$ \\
\hline Tourette syndrome & 1 & $3 \%$ & 1 & $3 \%$ \\
\hline Phobic anxiety disorder & 1 & $3 \%$ & 0 & $0 \%$ \\
\hline No diagnosis & 0 & $0 \%$ & I & $3 \%$ \\
\hline \multicolumn{5}{|l|}{$\begin{array}{l}\text { First concern according to par- } \\
\text { ents about child neuropsychia- } \\
\text { tric problems }\end{array}$} \\
\hline I-3 years & 20 & $43 \%$ & & \\
\hline$>3-7$ years & 23 & $50 \%$ & & \\
\hline \multicolumn{5}{|l|}{$\begin{array}{l}\text { The child's neuropsychiatric } \\
\text { problems affect his/her daily life } \\
\text { ( } n=46 \text { parents) }\end{array}$} \\
\hline No symptom/hardly any symptoms & 13 & $28 \%$ & & \\
\hline Symptoms occasionally & 10 & $22 \%$ & & \\
\hline Symptoms often & 29 & $63 \%$ & & \\
\hline Symptoms disturbing all the time & 2 & $4 \%$ & & \\
\hline \multicolumn{5}{|l|}{$\begin{array}{l}\text { Visit to the clinic/hospital of his/ } \\
\text { her neurocognitive disorder } \\
\text { earlier }\end{array}$} \\
\hline Yes & 14 & $30 \%$ & & \\
\hline No & 32 & $70 \%$ & & \\
\hline
\end{tabular}

(Continued) 
Table 2 (Continued).

\begin{tabular}{|c|c|c|c|c|}
\hline \multirow[t]{2}{*}{ Participating group } & \multirow[b]{2}{*}{$\mathbf{n}$} & \multirow[b]{2}{*}{$\%$} & \multicolumn{2}{|c|}{$\begin{array}{l}\text { Non- } \\
\text { partici- } \\
\text { pating } \\
\text { group }\end{array}$} \\
\hline & & & $\mathbf{n}$ & $\%$ \\
\hline \multicolumn{5}{|l|}{$\begin{array}{l}\text { Number of visits to the clinicl } \\
\text { hospital }\end{array}$} \\
\hline Once & 5 & $36 \%$ & & \\
\hline Twice & 4 & $29 \%$ & & \\
\hline$\geq 3$ times & 5 & $36 \%$ & & \\
\hline
\end{tabular}

"We want open communication in both directions during the child's evaluation process at the hospital".

"We hope that the staff has a genuine ability to listen to the parents".

The second main category is "Parents want more knowledge and support in daily life" including subdomains "Need to get knowledge about the child's symptoms and care", "Need to get knowledge about how to support the child's development", "Support for daily living", and "Economical support and possibilities to peer support". One parent wrote "I hope to get information about habilitation possibilities for the child".

"We want somebody to come home and observe and giving us concrete guidance in daily life".

"We hope somebody tells us about the child's diagnose and tells us what we need to do as parents".

The third main category was "Parents hope to get competent staff for their child and family" including sub domains "Professional staff" and "Organized/well planned care". One parent wrote, "we hope the personnel highlight the strengths of the child and support the child's self-esteem".

"We want professionals, who know about NDD and tells us what is going to happen in beforehand about evaluation-, care-, and rehabilitation processes".
The fourth main category was "Parents hope the whole family to be included by health professionals" including subcategories "All family members need attention", "Concrete help", and "To believe in tomorrow". One example from a parent is "We need knowledge about how the family as whole finds the strength to carry on".

"We want to know where to get help for the whole family".

"The family situation is always including all family members and we hope to get help as a family".

\section{Discussion}

The results from this study suggest that in families with children with NDD family health is connected to the experience of family functionality. Family health is affected positively if eg responsibilities concerning family chores are divided evenly in the family and everyone in the family participates. Furthermore, the experience of receiving social support from outside the family matters regarding the family health. This is in line with what Duffy $^{31}$ has proposed, that internal family dynamics and external environmental factors interrelate and affect the health promotion behaviors inside the family. Positive, although weak correlation, was also found in another study using FAFHES in pediatric intensive care between social support given by nurses and family health experienced by parents. ${ }^{23}$ In addition, earlier studies using FAFHES in families of adult patients with cardiac disease report an association between family health and family functionality. ${ }^{32}$ However, we found no correlation between social support and family functionallity which would have been expected considering the general knowledge and impression of the importance of support. Also, the parents' qualitative responses highlighted the need for social support in their parenthood. This suggests that other factors than social support, in addition to family health, might have an impact on functionality in families with children

Table 3 FAFHES questionnaire at baseline and three-months later.

\begin{tabular}{|c|c|c|c|c|c|c|c|c|}
\hline \multirow[t]{2}{*}{ Subdomains } & $\begin{array}{l}\text { Total } \\
n=42-46\end{array}$ & $\begin{array}{l}\text { Mothers } \\
n=29\end{array}$ & $\begin{array}{l}\text { Fathers } \\
n=17\end{array}$ & \multirow[t]{2}{*}{$p$-value } & $\begin{array}{l}3 \text { months } \\
n=27\end{array}$ & \multirow[t]{2}{*}{$p$-value } & $\begin{array}{l}\text { Mothers* } \\
\mathrm{n}=17\end{array}$ & \multirow[t]{2}{*}{$p$-value } \\
\hline & Mean (SD) & Mean (SD) & Mean (SD) & & Mean (SD) & & Mean (SD) & \\
\hline F Function & $4.6(0.8)$ & $4.5(0.9)$ & $4.6(0.6)$ & 0.793 & $4.3(0.6)$ & 0.119 & $4.6(0.9)$ & 0.760 \\
\hline F Health & $4.4(0.7)$ & $4.4(0.7)$ & $4.6(0.6)$ & 0.586 & $4.2(0.6)$ & 0.056 & $4.3(0.7)$ & 0.198 \\
\hline S Support & $3.7(1.3)$ & $3.8(1.3)$ & $3.5(1.3)$ & 0.576 & $3.5(1.3)$ & 0.158 & $3.7(1.1)$ & 0.591 \\
\hline
\end{tabular}

Note: *Paired sample $t$-test between mothers $(n=17)$ and fathers $(n=17)$ of the same child. 
Table 4 Results of the open-ended questions presented as four main categories that illustrate parents' hopes and expectations towards health care professionals.

\begin{tabular}{|c|c|c|}
\hline Reduction & Sub category & Main category \\
\hline $\begin{array}{l}\text { Interaction about/during the child's clinical visit } \\
\text { and therapies } \\
\text { Meetings } \\
\text { Regular appointments } \\
\text { Open communication } \\
\text { Open attitude } \\
\text { How to reach right professionals } \\
\text { Taking parent concerns seriously } \\
\text { Staff to have ability to listen } \\
\text { Staff to support parents' opinions if problems in } \\
\text { school } \\
\text { More time for discussion } \\
\text { Staff to have time for parents }\end{array}$ & $\begin{array}{l}\text { Interaction with staff } \\
\text { Communication between professionals in } \\
\text { school, daycare, and hospital } \\
\text { Hope to be listened to } \\
\text { Hope to get more time from personnel }\end{array}$ & Parents want dialog \\
\hline $\begin{array}{l}\text { Knowledge about neurocognitive symptoms } \\
\text { Knowledge about the diagnosis } \\
\text { Knowledge about the child's symptoms } \\
\text { Knowledge about child's medication } \\
\text { Knowledge about examinations } \\
\text { Knowledge about the educational possibilities } \\
\text { Knowledge about hobbies } \\
\text { Knowledge about habilitation } \\
\text { Knowledge about how to help the child with } \\
\text { learning difficulties } \\
\text { Knowledge about how to tell the child about } \\
\text { learning difficulties } \\
\text { Info about how to support the child with language } \\
\text { problems } \\
\text { Knowledge about parenting issues } \\
\text { Parenting advice to parents } \\
\text { Knowledge about how to help child manage } \\
\text { independently } \\
\text { Tips how to manage daily living at home and } \\
\text { daycare }\end{array}$ & $\begin{array}{l}\text { Need to get knowledge about the child's } \\
\text { symptoms and care } \\
\text { Need to get knowledge about how to support } \\
\text { the child's development } \\
\text { Support for daily living }\end{array}$ & $\begin{array}{l}\text { Parents want more knowledge and support } \\
\text { in daily life }\end{array}$ \\
\hline $\begin{array}{l}\text { Concrete help for daily living } \\
\text { Concrete help for daily demanding situations } \\
\text { Advice how to habilitate the child at home } \\
\text { Help to make routines for the whole family } \\
\text { Knowledge about social benefits } \\
\text { Guidance to find peer groups } \\
\text { Examples about other similar families }\end{array}$ & $\begin{array}{l}\text { Economical support and possibilities to peer } \\
\text { support }\end{array}$ & \\
\hline $\begin{array}{l}\text { Educated staff } \\
\text { Competent staff }\end{array}$ & Professional staff & \\
\hline
\end{tabular}

(Continued) 
Table 4 (Continued).

\begin{tabular}{|l|l|l|}
\hline Reduction & Sub category & Main category \\
\hline $\begin{array}{l}\text { Guidance in English } \\
\text { Guidance in Swedish } \\
\text { Staff to keep promises }\end{array}$ & & \\
Highlight the child's strengths & Parents hope to get competent staff for their \\
child and family \\
$\begin{array}{l}\text { Systematically organized care } \\
\text { Clear time schedules }\end{array}$ & Organized/well planned care & \\
\hline $\begin{array}{l}\text { Hope about noticing the whole family } \\
\text { Hope that somebody would arrange free time for } \\
\text { the parents as couple } \\
\text { Knowledge about how the family as whole can } \\
\text { find the strength to carry on } \\
\text { Help from family workers } \\
\text { Support for couple relationship } \\
\text { Childcare help }\end{array}$ & All family members need attention \\
$\begin{array}{l}\text { To get some help as parent to find the strength to } \\
\text { carry on }\end{array}$ & & \\
$\begin{array}{l}\text { To get some help in believing in future } \\
\text { To get support as a parent }\end{array}$ & Concrete help & Parents hope the whole family to be \\
\hline
\end{tabular}

with NDD. For example, we have not studied if the parents themselves had NDD deficits which might have an impact on parenthood and which is likely considering the heritability of NDD disorders.

Parents of the children with NDD who visited the neurocognitive units at $\mathrm{HUH}$ for the first time reported family functionality to be generally quite good. The fact that the relationship between parents was assessed as quite good might suggest that the parents support each other in their parenthood. Parents' own opinions about having strength during parenthood seems to be connected to their opinion of having good health and good relationship with the other parent. Similar results were reported from pediatric intensive care as the main outcome where parents using FAFHES considered their family functioning and health to be good. ${ }^{23}$

No statistically significant difference was found in this study between fathers and mothers, although studies made before have shown the differences between parents eg, quality of life and stress experiences and also unique support needs. ${ }^{33,34}$ Reilly and colleagues ${ }^{35}$ have in their study reported eg, how epilepsy of young children can have a very significant impact on parental well-being and how mothers particular are being at risk. The same report suggests screening for mental health problems on a regular basis in parents to children with epilepsy. ${ }^{35}$ Another study shows fathers rating their children as having less problems than mothers. ${ }^{36}$ There are also findings that suggest that depressive symptoms found in mothers of children with ASD may be attributed both to the increased stress of raising a child with ASD as well as autistic features in the mothers. ${ }^{37}$ These kinds of findings did not appear in our study.

It is known that parents' perceptions of family functionality are often affected by the symptoms of other family members. ${ }^{38}$ This study emphasizes the parental perspective and how NDD often affects the whole family. Family functionality and the emotional climate in the family are significant factors regarding family health. Maybe this is the reason why parents in this study expressed their hopes for the whole family to be noticed and taking into consideration as a unit. Moreover, according to these parents, siblings situation in the families need more attention.

Parents expressed the need for additional communication and considered the dialogue with professionals concerning their child as very important. By maintaining a dialogue with the parents, the family perspective can be included and a deeper understanding of the child is provided. 
The open-ended questions tapped into the parents' hopes and expectations. Although parents felt they managed well as parents, they all had similar hopes about more collaboration between professionals. This has also been confirmed in other studies. ${ }^{39-41}$ Parents hope for practical guidance in their daily life, for advice and concrete aid in how to deal with daily demands in raising their child. Parents also hoped for more individualized family focused healthcare such as individualized information regarding the child. Parents further expressed the need for tailored support to all family members, and for peer support from other families with children with similar symptoms. This was mentioned as an important "parenthood strengthening factor".

A systematic review by Goode and colleagues ${ }^{42}$ revealed that despite the wide use of several parent programmes and intervention approaches, there are still significant gaps in knowledge regarding the effectiveness of ADHD nonpharmacological treatments. The information delivered by parents in this study can fill an important gap of knowledge when developing interventions for this target group.

The study showed that FAFHES questionnaire results obtained three months after the initial round yielded similar results as at the first time. This suggests that family functionality and health did not improve during the threemonth-period, even though families received an assessment of the child and a habilitation plan. Possible explanations for this are that three months of follow-up is not long enough for more positive changes in functionality and health factors in the families, or that diagnosis/intervention for the child does not affect family functionality or health.

\section{Limitations}

A major limitation of the study is the very considerable attrition, and only $43 \%$ of the families who agreed to participate actually completed the FAFHES questionnaire. However, there was no obvious difference between questionnaire completers and non-completers. Nevertheless, it is known from other studies that, overall, families with certain types of NDDs (for instance ADHD) are less likely to adhere to agreed protocols or appointments. The generalisability of the findings to all families with children with NDDs is therefore in doubt, and it is possible that more problems related to family functionality and health might have been present in non-responding families.

The strength of the study is the information that responding parents shared concerning their everyday life with a child having NDD and their expectations vis-a-vis health professionals. This information confirms that there is a need to tailor family interventions for this target group.

\section{Conclusion}

Family functionality was found to positively correlate with family health. Also, experience of strength in parenthood correlated to family health. Neither parental age nor number of siblings correlated with any of FAFHES subdomains. The quality of the relationship between the parents, experience of own health, and age of onset of child NDD problems correlated negatively with family functionality. Surprisingly, no correlation between social support and functionality was found. Negative correlations were also found between Family health and quality of relations between parents. No differences between mothers and fathers were found. There were no significant changes in parents' experience of family functionality, health, and social support over a three-month follow-up period. Parents wanted dialogue, information, and concrete guidance from staff in daily matters regarding their child.

\section{Acknowledgments}

Our warmest thanks to the families participating in this study, to the staff at the HUH, and to Professor Päivi Åstedt-Kurki and her copyright holders at Tampere University, who gave permission to modify and use the FAFHES questionnaire for this study.

\section{Disclosure}

The authors report no conflicts of interest in this work.

\section{References}

1. Gillberg C. The ESSENCE in child psychiatry: early symptomatic syndromes eliciting neurodevelopmental clinical examinations. Res Dev Disabil. 2010;31(6):1543-1551. doi:10.1016/j.ridd.2010.06.002

2. Gillberg C. [ESSENCE gathers the diagnoses into a whole]. Lakartidningen. 2014;111(39):1643-1646.

3. Chen Q, Brikell I, Lichtenstein P, et al. Familial aggregation of attention-deficit/hyperactivity disorder. $J$ Child Psychol Psychiatry. 2017;58(3):231-239. doi:10.1111/jcpp.2017.58.issue-3

4. Biederman J. Attention-deficit/hyperactivity disorder: a selective overview. Biol Psychiatry. 2005;57(11):1215-1220. doi:10.1016/j. biopsych.2004.10.020

5. Jj H, Em D, Rr A, Dc R, Di B. The genetic and environmental contributions to attention deficit hyperactivity disorder as measured by the conners' rating scales-revised. Am J Psychiatry. 2005;162 (9):1614-1620. doi:10.1176/appi.ajp.162.9.1614

6. Robert C, Pasquier L, Cohen D, et al. Role of genetics in the etiology of autistic spectrum disorder: towards a hierarchical diagnostic strategy. Int $J$ Mol Sci. 2017;18(3):618. doi:10.3390/ ijms 18030618

7. Tick B, Colvert E, McEwen F, et al. Autism Spectrum Disorders and other mental health problems: exploring etiological overlaps and phenotypic causal associations. J Am Acad Child Adolesc Psychiatry. 2016;55(2):106-113. doi:10.1016/j.jaac.2015.11.013 
8. Biederman J. Introduction: new developments in the treatment of attention deficit/hyperactivity disorder. J Clin Psychiatry. 2006;67 (8):4-6.

9. Herring S, Gray K, Taffe J, Tonge B, Sweeney D, Einfeld S. Behaviour and emotional problems in toddlers with pervasive developmental disorders and developmental delay: associations with parental mental health and family functioning. J Intellect Disabil Res. 2006;50(Pt 12):874-882. doi:10.1111/j.1365-2788.2006.00904.x

10. Deault LC. A systematic review of parenting in relation to the development of comorbidities and functional impairments in children with attention-deficit/hyperactivity disorder (ADHD). Child Psychiatry Hum Dev. 2010;41(2):168-192. doi:10.1007/s10578-009-0159-4

11. Duarte CS, Bordin IA, Yazigi L, Mooney J. Factors associated with stress in mothers of children with autism. Autism. 2005;9 (4):416-427. doi:10.1177/1362361305056081

12. Falk NH, Norris K, Quinn MG. The factors predicting stress, anxiety and depression in the parents of children with autism. J Autism Dev Disord. 2014;44(12):3185-3203. doi:10.1007/s10803-014-2189-4

13. Pimentel MJ, Vieira-Santos S, Santos V, Vale MC. Mothers of children with attention deficit/hyperactivity disorder: relationship among parenting stress, parental practices and child behaviour. Atten Defic Hyperact Disord. 2011;3(1):61-68. doi:10.1007/s12402-011-0053-3

14. van Steijn DJ, Oerlemans AM, van Aken MA, Buitelaar JK, Rommelse NN. The reciprocal relationship of ASD, ADHD, depressive symptoms and stress in parents of children with ASD and/or ADHD. J Autism Dev Disord. 2014;44(5):1064-1076. doi:10.1007/ s10803-013-1958-9

15. Dadashzadeh H, Amiri S, Atapour A, Abdi S, Asadian M. Personality profile of parents of children with attention deficit hyperactivity disorder. Sci World J. 2014;1-5. doi:10.1155/2014/212614

16. Margari F, Craig F, Petruzzelli G, Lamanna A, Matera E, Margari L. Parents psychopathology of children with attention deficit hyperactivity disorder. Res Dev Disabil. 2013;34(3):1036-1043. doi:10.1016/ j.ridd.2012.12.001

17. Johnston C, Mash EJ. Families of children with attention-deficit/ hyperactivity disorder: review and recommendations for future research. Clin Child Fam Psychol Rev. 2001;4(3):183-207.

18. Barlow J, Smailagic N, Huband N, Roloff V, Bennett C. Group-based parent training programmes for improving parental psychosocial health. Cochrane Database Syst Rev. 2014;(5):Cd002020. doi:10.1002/14651858.CD002020.pub4.

19. Jackson AC, Liang RP, Frydenberg E, Higgins RO, Murphy BM. Parent education programmes for special health care needs children: a systematic review. J Clin Nurs. 2016;25(11-12:1528-1547. doi:10.1111/jocn.13178

20. Wachtel K, Carter AS. Reaction to diagnosis and parenting styles among mothers of young children with ASDs. Autism. 2008;12 (5):575-594. doi:10.1177/1362361308094505

21. Ho SW, Chien WT, Wang LQ. Parents' perceptions of care-giving to a child with attention deficit hyperactivity disorder: an exploratory study. Contemp Nurse. 2011;40(1):41-56. doi:10.5172/conu.2011.40.1.41

22. Wiener J, Biondic D, Grimbos T, Herbert M. Parenting stress of parents of adolescents with attention-deficit hyperactivity disorder. J Abnorm Child Psychol. 2016;44(3):561-574. doi:10.1007/s10802-015-0050-7

23. Hakio N, Rantanen A, Astedt-Kurki P, Suominen T. Parents' experiences of family functioning, health and social support provided by nurses - a pilot study in paediatric intensive care. Intensive Crit Care Nurs. 2015;31(1):29-37. doi:10.1016/j.iccn.2014.08.001

24. Tarkka MT, Paavilainen E, Lehti K, Astedt-Kurki P. In-hospital social support for families of heart patients. J Clin Nurs. 2003;12(5):736-743.

25. Astedt-Kurki P, Lehti K, Tarkka MT, Paavilainen E. Determinants of perceived health in families of patients with heart disease. $J A d v$ Nurs. 2004;48(2):115-123. doi:10.1111/j.1365-2648.2004.03178.x
26. Astedt-Kurki P, Tarkka MT, Rikala MR, Lehti K, Paavilainen E. Further testing of a family nursing instrument (FAFHES). Int $J$ Nurs Stud. 2009;46(3):350-359. doi:10.1016/j.ijnurstu. 2008.01.008

27. Aho AL, Tarkka MT, Åstedt-Kurki P, Kaunonen M. Fathers' experience of social support after the death of a child. Am J Men's Health. 2009;3(2):93-103. doi:10.1177/1557988307302094

28. Harju E, Rantanen A, Tarkka MT, Astedt-Kurki P. Perceived family health in persons with prostate cancer and their family members. J Clin Nurs. 2013;21(3-4):544-554. doi:10.1111/j.1365-2702.2011.03775.x

29. Lepisto S, Ellonen N, Helminen M, Paavilainen E. The family health, functioning, social support and child maltreatment risk of families expecting a baby. J Clin Nurs. 2017;26(15-16:2439-2451. doi:10.1111/jocn. 13602

30. Graneheim UH, Lindgren BM, Lundman B. Methodological challenges in qualitative content analysis: a discussion paper. Nurse Educ Today. 2017;56:29-34. doi:10.1016/j.nedt.2017.06.002

31. Duffy ME. Health promotion in the family: current findings and directives for nursing research. J Adv Nurs. 1988;13(1):109-117.

32. Paavilainen E, Lehti K, Astedt-Kurki P, Tarkka MT. Family functioning assessed by family members in Finnish families of heart patients. Eur J Cardiovasc Nurs. 2006;5(1):54-59. doi:10.1016/j.ejcnurse.2005.10.002

33. Hartley SL, Schultz HM. Support needs of fathers and mothers of children and adolescents with autism spectrum disorder. J Autism Dev Disord. 2015;45(6):1636-1648. doi:10.1007/s10803-014-2318-0

34. Pisula E, Porebowicz-Dorsmann A. Family functioning, parenting stress and quality of life in mothers and fathers of Polish children with high functioning autism or Asperger syndrome. PLoS One. 2017;12(10):e0186536. doi:10.1371/journal.pone.0186536

35. Reilly C, Atkinson P, Memon A, et al. Symptoms of depression, anxiety, and stress in parents of young children with epilepsy: a case controlled population-based study. Epilepsy Behavior. 2018;80:177-183. doi:10.1016/j.yebeh.2017.12.020

36. Sollie H, Larsson B, Mørch WT. Comparison of mother, father, and teacher reports of ADHD core symptoms in a sample of child psychiatric outpatients. $J$ Atten Disord. 2013;17(8):699-710. doi:10.1177/1087054711436010

37. Ingersoll B, Meyer K, Becker MW. Increased rates of depressed mood in mothers of children with ASD associated with the presence of the broader autism phenotype. Autism Research. 2011;4 (2):143-148. doi:10.1002/aur.170

38. Williamson D, Johnston C. Marital and coparenting relationships: associations with parent and child symptoms of ADHD. J Atten Disord. 2016;20(8):684-694. doi:10.1177/1087054712471717

39. Gustavsson S, Gremyr I, Kenne Sarenmalm E. Designing quality of care - contributions from parents: parents' experiences of care processes in paediatric care and their contribution to improvements of the care process in collaboration with healthcare professionals. J Clin Nurs. 2016;25(5-6):742-751. doi:10.1111/ jocn. 13050

40. Potvin MC, Prelock PA, Savard L. Supporting children with autism and their families: a culturally responsive family-driven interprofessional process. Pediatr Clin North Am. 2018;65(1):47-57. doi:10.1016/j.pcl.2017.08.020

41. Widmark C, Sandahl C, Piuva K, Bergman D. Parents' experiences of collaboration between welfare professionals regarding children with anxiety or depression - an explorative study. Int $J$ Interg Care. 2013;31:13e045.

42. Goode AP, Coeytaux RR, Maslow GR, et al. AR. Nonpharmacologic treatments for attention-deficit/hyperactivity disorder: a systematic review. Pediatrics. 2018;141(6):e20180094. doi:10.1542/peds.20180094 


\section{Publish your work in this journal}

Neuropsychiatric Disease and Treatment is an international, peerreviewed journal of clinical therapeutics and pharmacology focusing on concise rapid reporting of clinical or pre-clinical studies on a range of neuropsychiatric and neurological disorders. This journal is indexed on PubMed Central, the 'PsycINFO' database and CAS, and is the official journal of The International Neuropsychiatric Association (INA). The manuscript management system is completely online and includes a very quick and fair peer-review system, which is all easy to use. Visit http://www.dovepress.com/testimonials.php to read real quotes from published authors. 